\title{
AN ANALYSIS OF THE HABITAT OF THE GREATER ONE-HORNED \\ RHINOCEROS RHINOCEROS UNICORNIS (MAMMALIA: PERISSODACTYLA: Rhinocerotidae) at the Chitwan National Park, Nepal
}

\author{
Vivek Thapa ${ }^{1}$, Miguel F. Acevedo ${ }^{2} \&$ Kul P. Limbu ${ }^{3}$ \\ ${ }^{1}$ Institute of Applied Sciences, Department of Biological Sciences, University of North Texas, P.O. Box 310559, Denton, \\ TX 76203 USA \\ ${ }^{2}$ Departments of Electrical Engineering and Geography, University of North Texas, 3940 North Elm Street, Denton, TX \\ 76207 USA \\ ${ }^{3}$ Department of Zoology, Post Graduate Campus, Tribhuvan University, PO Box: 137, Biratnagar, Nepal \\ ${ }^{1}$ thapaviv@yahoo.com (corresponding author), ${ }^{2}$ miguel.acevedo@unt.edu, ${ }^{3}$ limbukp@gmail.com
}

\begin{abstract}
We used Geographic Information Systems (GIS) and landscape-level data obtained from remote sensing sources to build a habitat suitability index model (HSI) for the Greater One-horned Rhinoceros Rhinoceros unicornis. The model was based primarily on important habitat requisites of the modeled species, especially food and cover. We extracted food and cover from land cover map and ran focal statistics to determine their proportion in a neighborhood of 70x70 pixels that accounts for the animal's average mean annual home range, which is $\sim 4 \mathrm{~km}^{2}=400$ ha $=70 \times 70$ pixels $\times 900 \mathrm{~m}^{2}=4410000 / 10000=441$ ha. We used two arbitrarily selected parameters $a$ and $T c$ to observe the impacts of food and cover on the HSI. We performed sensitivity analysis by varying values of parameters around their nominal, which revealed that the HSI value of a pixel is changed with uncertainty with very low values of a fraction of the food or cover. We identified four habitat types from the HSI map. We used patch and class metrics of FRAGSTATS program to estimate the amount and fragmentation of each habitat type. The metrics provided composition and configuration status for all four habitat types. We found a presence of a total of 476 patches with $517.82 \mathrm{~km}^{2}$ belonging to suitable habitat type. These areas can be targeted for management, monitoring and improvement to provide habitat for the target and sympatric species.
\end{abstract}

Keywords: Chitwan National Park, GIS, Greater One-horned Rhinoceros, habitat fragmentation, habitat suitability index model, remote sensing.
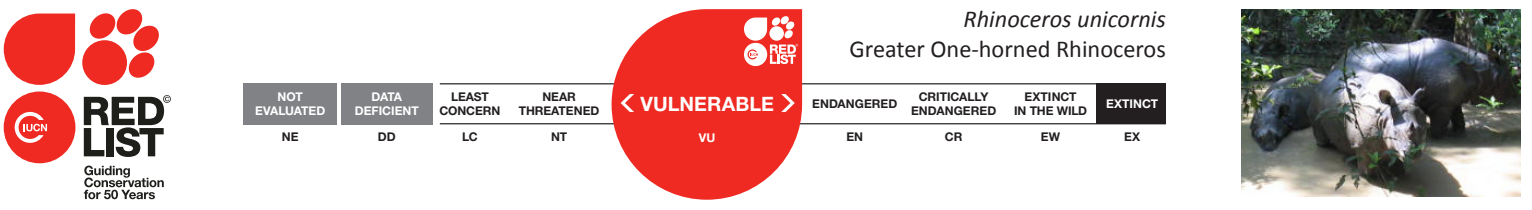

DOI: http://dx.doi.org/10.11609/JoTT.03698.6313-25

Editor: Kees Rookmaaker, Rhino Resource Center, United Kingdom.

Date of publication: 26 September 2014 (online \& print)

Manuscript details: Ms \# 03698 | Received 14 August 2013 | Final received 03 September 2014 | Finally accepted 08 September 2014

Citation: Thapa, V., M.F. Acevedo \& K.P. Limbu (2014). An analysis of the habitat of the Greater One-horned Rhinoceros Rhinoceros unicornis (Mammalia: Perissodactyla: Rhinocerotidae) at the Chitwan National Park, Nepal. Journal of Threatened Taxa 6(10): 6313-6325; http://dx.doi.org/10.11609/JoTT.o3698.6313-25

Copyright: (C) Thapa et al. 2014. Creative Commons Attribution 4.0 International License. JoTT allows unrestricted use of this article in any medium, reproduction and distribution by providing adequate credit to the authors and the source of publication.

Funding: U.S. National Science Foundation (NSF) for partial funding for this study under the grant CNH BCS-0216722.

Competing Interest: The authors declare no competing interests.

Author Contribution: VT designed, proposed and conducted entire research and performed GIS and remote sensing work. He wrote the paper with intermittent assistance from Miguel Acevdo. MFA was graduate professor for Vivek Thapa at University of North Texas. He supervised all work of the study and the paper and performed sensitivity analysis. He edited some sections of the paper. KPL was heavily involved in the field work at Chitwan National Park, Nepal.

Author Details: See end of this article.

Acknowledgements: We thank U.S. National Science Foundation (NSF) for partial funding for this study under the grant CNH BCS-0216722. We acknowledge the assistance of several individuals such as the staff of National Trust for Nature Conservation (formerly known as King Mahendra Trust for nature Conservation), especially Mr. P. Khanal and the guides who offered the first author (V.T.) immense help during the adventurous field trip in the year of 2004-2005. The assistance of Dr. J. Kennedy and Dr. E. Zimmerman during the project was crucial. We thank O. Sanchez, Editor, College of Engineering, University of North Texas, for constructive and extensive editorial comments. 


\section{INTRODUCTION}

The Greater One-horned Rhinoceros Rhinoceros unicornis is a Vulnerable species (Talukdar et al. 2008) (Image 1). They were once widely distributed throughout the Brahmaputra, Indus, and Ganges plains of South Asia, but indiscriminate poaching and unprecedented habitat loss nearly pushed them to extinction (Laurie 1982; Cohn 1988; Dinerstein \& Price 1991; Jnawali \& Wegge 1993; Dinerstein 2003; Harini et al. 2008). They are now restricted to small isolated populations on the Indian subcontinent, mainly in India and Nepal (Laurie 1982; Rookmaaker 1984; Dinerstein \& McCracken 1990; Dinerstein \& Price 1991). In Nepal, Dinerstein \& Price (1991) recognized four distinct subpopulations in Chitwan National Park (CNP hereafter), based on their isolation. They used physical barriers such as rivers and low mountains and ecological boundaries such as sal forests and agricultural lands to identify the four subpopulations of the Sauraha (1), the BandarjholaNarayani River (2), the west (3) and the south (4) (Fig. 1). They also reported frequent movement of animals from far-east of the park boundary that was initially thought as a separate population by Laurie (1982). They combined this population with the Sauraha, which historically had the highest population of rhinos and was most intensively studied due to easier access from major cities such as Narayanghat and Kathmandu, better accommodations (the park elephants, hotels) and communications than the rest of the park (Mishra 1982a; Lekhmul 1989).

Dinerstein (2003) reported a small mean annual home range of breeding male and female to be $4.3 \mathrm{~km}^{2}$ and $3.5 \mathrm{~km}^{2}$ respectively. The reason for such a small home range is the presence of prime habitats and relatively less

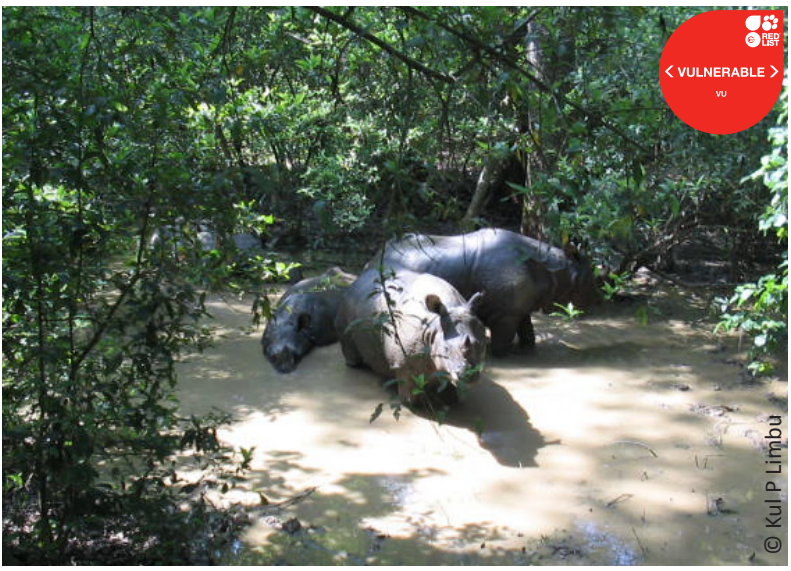

Image 1. Greater One-horned Rhinoceros Rhinoceros unicornis competition from sympatric species such as hog deer and the absence of swamp deer in CNP as compared to Bardia National Park (Jnawali \& Wegge 1993; Jnawali 1995; Odden et al. 2005; Wegge et al. 2006). The prime habitats include a mosaic of grasslands, oxbow lakes, Sal forests, and alluvial floodplains. However, most research reports indicate the importance of grassland habitats mixed with wallows and some cover for their survival. Nonetheless, rhinos do travel far if the habitat fails to provide enough food and water (Jnawali \& Wegge 1993; Jnawali 1995). The existing literature on monitoring rhino habitats of Chitwan Valley is scarce since most papers on rhino focus on biological and ecological aspects of the species (Laurie 1978; Owen-Smith 1988; Lott \& McCoy 1995; Dinerstein 2003). Satellite remote sensing and GIS (Geographic Information Systems) offer an opportunity to contribute knowledge about the habitat. These technologies are increasingly used to model spatial information about wildlife habitat (Porwal et al. 1996; Sharma et al. 2004). In addition, remote sensing coupled with field work and GIS has proven effective in deriving much needed data for habitat monitoring, conservation and management and such data is lacking for Greater One-horned Rhinoceros (Laperriere et al. 1980; Porwal \& Roy 1996; Innes \& Koch 1998; Berlanga-Robles \& RuizLuna 2002; Dinerstein 2003).

Satellite images represent important data sources to develop vegetation maps for large areas. Particularly, Landsat 7 Enhanced Thematic Mapper-Plus (ETM+) images have been proven useful and cost-effective for large-scale habitat analysis (McClain \& Porter 2000). A vegetation map derived from remote sensing can be processed to determine habitat suitability by using habitat evaluation procedures (HEP) leading to the development of a map of habitat suitability index (HSI) (Allen 1982). HEP involves collection of information on behavior, food habits, mating season, taxonomy and the animal's position in the trophic niche of a target species in order to evaluate its habitat (Porwal \& Roy 1996; Sharma et al. 2004). The resulting HSI map can aid in the understanding and management of habitat for this species. It could be used to locate, target and manage areas of suitable habitats and therefore support conservation and restoration program in CNP. In addition, HSI maps can be further analyzed to determine spatial structure, particularly fragmentation, of suitable habitat. The FRAGSTATS program (McGarigal \& Marks 1994) offers the capabilities to calculate several metrics related to spatial structure and fragmentation.

The major objective of this paper is to determine the amount and spatial structure of the remaining 
rhino habitat in CNP. Our research consisted of three major components: (1) developing a land-cover map emphasizing the vegetation of the CNP by using a Landsat ETM+ image, (2) developing HEP to generate a HSI map, and (3) determining the spatial distribution of the current suitable habitat area for rhinoceroses via fragmentation metrics.

\section{METHODS}

\section{Study Area}

CNP is located in the lowlands of Nepal along the northern border of India at an elevation of $110-850 \mathrm{~m}$ and covers $932 \mathrm{~km}^{2}$ of park area (Fig. 1) and $750 \mathrm{~km}^{2}$ of buffer zone in the Chitwan and Makawanpur districts (DNPWC 2009). The buffer zone (community forest) is managed by the locals and is mainly used for fuel and fodder collection. In addition, it is home to several rhinos and other wildlife. Although the area is almost flat, the terrain consists of some depressions and Churia hills at an elevation of $\sim 300 \mathrm{~m}$. This hill, located in between Rapti River to the north and Reu River to the south, forms a physical barrier to the sub populations of rhinos residing on their banks. Geographically, the park lies from $83^{\circ} 41^{\prime}-83^{\circ} 49^{\prime} \mathrm{E}$ longitudes and from $27^{\circ} 01^{\prime}-$ $27^{\circ} 41^{\prime} \mathrm{N}$. CNP's bordered in the northeast, northwest and west are Rapti and Naryani rivers which in turn are bordered by privately owned land used primarily for agriculture. On the east, it is bordered by Parsa National Park. Climate is subtropical, with temperatures rising to approximately $37^{\circ} \mathrm{C}$ on a typical summer day. Mean annual precipitation is $2400 \mathrm{~mm}$ with $90 \%$ of it falling during the period from May to September.

Vegetation consists of deciduous, mixed, and riverine forests punctuated by grassland communities. Sal forests are a prominent forest type, covering $70 \%$ of the park area dominated by trees of Shorea robusta and occur on upland, well-drained slopes rarely used by the rhinoceroses but frequented by wild elephants (Laurie 1982). The riverine forest association is composed of Trewia nudiflora, Bombax ceiba, Acacia catechu, and Dalbergia sisoo frequently used by the rhinoceros and they seek out fruits of T. nudiflora during summer (Lekhmul 1989; Dinerstein \& Price 1991; Jnawali \& Wegge 1993; Dinerstein 2003; Rawat 2005; Subedi

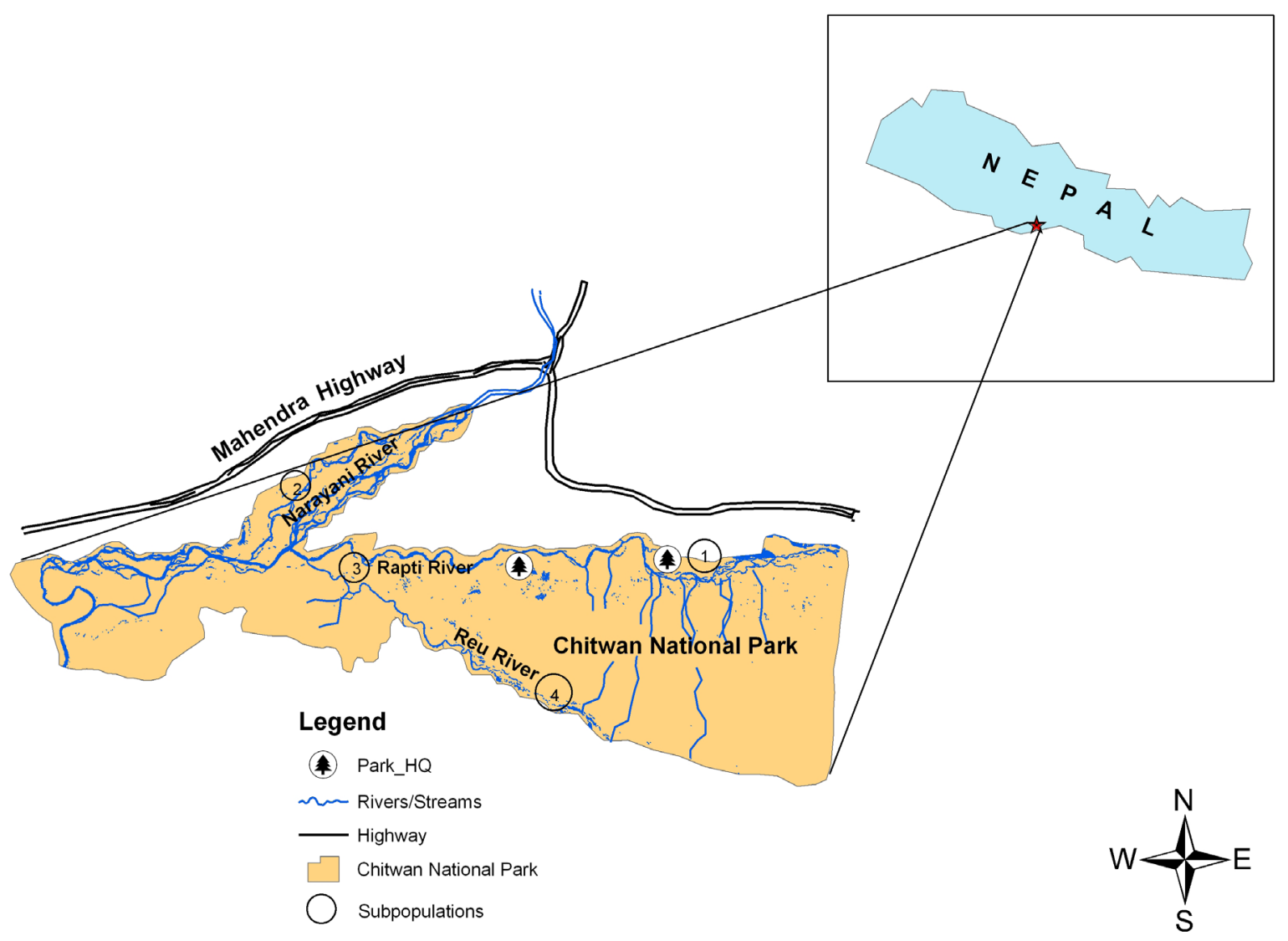

Figure 1. The study area is located on the southern lowlands of Nepal bordering India. 
2012).

The physiographic distribution of tall grasslands is also noteworthy. The grassland habitat associations included either monospecific stands of tall grass species of Saccharum spontaneum (4-6 m); S. benghalensis, Narenga porphyrocoma, and Themeda arundinacea (5-7 m) or mixed with short grass species of Imperata cylindrica, Chrysopogon aciculatus, Eragrostis spp. and several others (Lekhmul 1989; Dinerstein 1989; Dinerstein \& Price 1991; Dinerstein 2003). The short grasses usually occur within tall grasslands and are intensively grazed by the rhinos. According to Dinerstein (2003), the aforementioned grass species occupied approximately $15 \%$ of the total park area and occurred on the higher terraces of the floodplain.

Another tall grass species, S. spontaneum, is the first to colonize the major river banks after the retreat of annual monsoon floods. It often occurs in pure stands and its thickness ranges from less than $100 \mathrm{~m}$ to more than $1 \mathrm{~km}$ in width and this type of grassland accounts for only $5 \%$ of the total park area (Dinerstein 2003). Among the grassland types, the rhinoceros seeks out $S$. spontaneum as it is the most nutritious of available tall grass species of Chitwan Valley (Laurie 1982; Lekhmul 1988; Dinerstein \& Price 1991; Dinerstein 2003; Subedi 2012).

\section{Satellite Data Selection and Processing}

We selected one ETM+ image for analysis based on criteria of desired geographic coverage, cloud-free conditions, and date (for seasonal considerations). Single-date scene (path 142 / row 41 , collected in 12 April 2003) from early summer or pre-monsoon (midFebruary to mid-June) was considered optimal because the deciduous trees are leafless enhancing the chances of discriminating deciduous from evergreen forests (Harini \& Gadgil 1999). The ETM+ images provide multispectral coverage for seven spectral bands in the visible (TM1, TM2, TM3), near-infrared (NIR TM4), mid infrared (MIR TM5, TM7) and thermal portions (TM 6) of the electromagnetic spectrum. Vegetation pixels are pronounced in TM4 $(0.7-0.9 \mu \mathrm{m})$. The spatial resolution of these bands is $30 \mathrm{~m}$ except for the thermal which is $60 \mathrm{~m}$. Because of this coarse resolution, we excluded thermal band from analysis. The image also provides a panchromatic spectral band with better spatial resolution (15m), which is commonly used for producing quality fusion imagery to obtain richer information in the spatial and spectral domain (Choi et al. 2005).

We geo-referenced the image using ground control points (GCPs) collected from topographic maps of
1:25000. We used locations of park headquarters, small towns, hotels, army posts and naturally visible features such as lakes to collect GCPs in order to reduce geometric and location distortion in the image (Hardison 2003). We used the image as a guide map during our field work in 2004 and 2005. In 2004, we collected more than 800 ground truth reference points using global positioning systems (GPS). Although there is no standard minimum distance between ground truth points, we separated points by at least $150 \mathrm{~m}$ in order to avoid overlap. In 2005, we made another trip to collect additional GPS points (20) of confused pixels (to be explained with detail in the results section). Each point was accompanied with notes of vegetation and soil type, moisture regime and elevation. We used half of the points to conduct supervised classification of eight land cover types, by employing the maximum likelihood algorithm (Harini \& Gadgil 1999). The eight land cover types were water, sand, grassland, agriculture, wetland, settlements, mixed and sal forest (Fig. 2). Our clipped image contained some agricultural lands, settlements and buffer zone adjacent to CNP. Therefore, we defined a separate class as agriculture and settlement as rhinos do venture out to nearby fields especially during night and sometimes become a source of wildlife-people conflict (Nepal \& Weber 1995; Studsrod \& Wegge 1995).

We used the other half of the ground-truth points to assess classification accuracy (Table 1). Generally, random points are used as a reference class to assess accuracy. However, in our case, we used a set of the ground-truth points as a reference class and compared with classified image class values to evaluate accuracy. This set of ground-truth points employed for evaluation was different from the set employed for classification. We derived error matrix that provide several statistics

Table 1. Errors of commission (User's Accuracy), errors of omission (Producer's Accuracy), and kappa statistics for classification of 2003 Landsat ETM image [Overall accuracy was $69.90 \%$.]

\begin{tabular}{|c|l|c|c|c|}
\hline & Classes & $\begin{array}{c}\text { Producer's } \\
\text { Accuracy (\%) }\end{array}$ & $\begin{array}{c}\text { User's } \\
\text { Accuracy (\%) }\end{array}$ & $\begin{array}{c}\text { Kappa } \\
\text { Statistics }\end{array}$ \\
\hline 1 & Water & 55.17 & 94.12 & 0.9365 \\
\hline 2 & Wetland & 100.00 & 75.00 & 0.7441 \\
\hline 3 & Agriculture & 96.05 & 50.34 & 0.3840 \\
\hline 4 & Settlement & 0.00 & 0.00 & 0.0000 \\
\hline 5 & Sand & 52.38 & 91.67 & 0.9119 \\
\hline 6 & Sal Forest & 87.65 & 84.52 & 0.8049 \\
\hline 7 & Mixed Forest & 52.54 & 81.58 & 0.7832 \\
\hline 8 & Grassland & 61.76 & 75.00 & 0.6621 \\
\hline
\end{tabular}




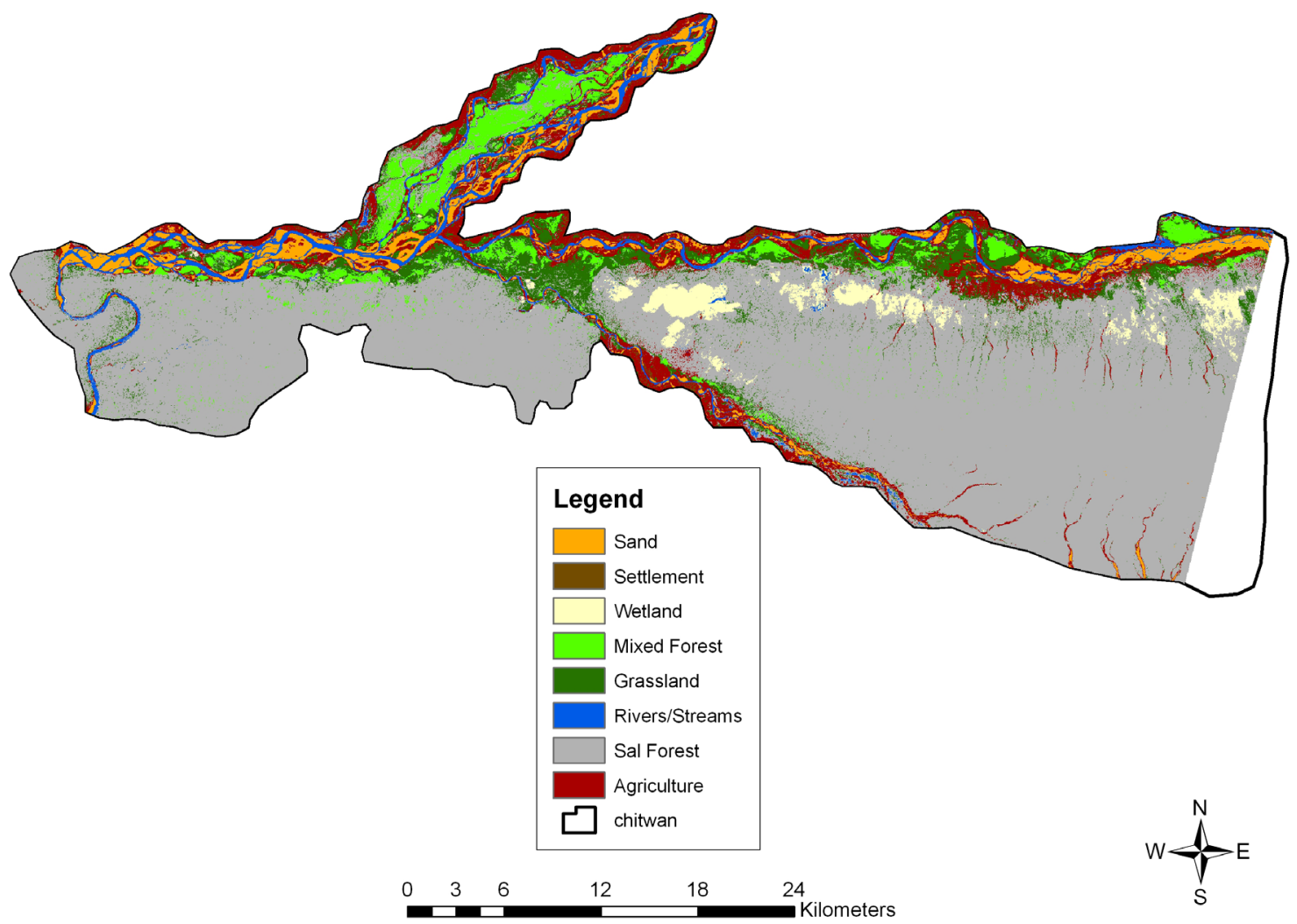

Figure 2. Supervised classified image of CNP.

including overall accuracy, omission and commission errors and kappa statistics or KHAT (measures agreement between classified and reference data). KHAT = 1 if agreement is $100 \%$.

\section{Habitat Suitability Index (HSI) and FRAGSTATS}

According to Dettki et al. (2003), two approaches are used to assess wildlife habitat relationships: process and empirical. Process-oriented models assess plausible causal relationships or functional processes underlying habitat use and provide a more general conceptual framework. In contrast, empirical models analyze data on habitat use and habitat characteristics collected at specific sites.

Process-oriented HSI models use habitat requisites or parameters such as food, cover, and proximity to water as input variables to a function providing a dimensionless $0.0-1.0$ index, where 0 and 1 indicates unsuitable and optimum habitat conditions respectively (Mitchell et al. 2002; Dettki et al. 2003). This function is determined by assumptions on how each one of the habitat requisites and their combination affect suitability and evaluate aptness of a habitat (Porwal et al. 1996; Dettki et al. 2003). We adopted a process- oriented approach to develop a heuristic HSI model for the Greater One-horned Rhinoceros inspired by moose habitat analysis of Dettki et al. (2003). Even though both species differ in habitat use, the model is applicable to any wildlife as it simply requires specific habitat use parameters. To estimate these parameters, we derived detailed rhino habitat use information from several published papers and field observations (Laurie 1982; Dinerstein \& Wemmer 1988; Lekhmul 1988; OwenSmith 1988; Dinerstein \& Price 1991; Jnawali \& Wegge 1993; Dinerstein 2003; Subedi 2012). We made two major assumptions while constructing the HSI model for the rhino. First, we assumed that existing information on habitat use by the animal can be translated to data related to model parameter values. Second, we assumed that food and cover requirements are more important than water requirement because water is available year round.

We used presence of grass, and forest in a neighborhood of $70 \times 70$ grid of a target pixel as input variables to calculate the HSI value for that pixel. The neighborhood size was determined according to the animal's average mean annual home range, which is $\sim 4 \mathrm{~km}^{2}=400 \mathrm{ha}=70 \times 70$ pixels $\times 900 \mathrm{~m}^{2}=4410000 / 10000$ 
$=441$ ha. We selected focal over block statistics to calculate the HSI value of each pixel. Focal functions assign a value for each processing cell and allow overlap while block statistics do not allow overlap (all cells within the block receive identical value). We extracted food (grass and agriculture) and cover (sal forest and mixed forest) from the land cover map and ran focal statistics to calculate proportion of food and cover in a neighborhood, denoted by $x f$ and $x c$ respectively. These were then used in the following way.

We define the suitability Sf and Sc for food and cover as

$$
S f=\left\{\begin{array}{lr}
x f / T f \text { when } x f<T f \\
1 \quad \text { when } x f \geq T f
\end{array}\right.
$$

and

$$
S c=\left\{\begin{array}{l}
x c / T c \text { when } c<T c \\
1 \quad \text { when } c \geq T c
\end{array}\right.
$$

where $T f$ and $T c$ are parameters defining a threshold of each factor to obtain maximum suitability. These threshold parameters are determined in the following manner.

For food, a large rhino eats between $60-80 \mathrm{~kg}$ a day fresh weight and spends most of its time browsing or grazing (Dinerstein 2003). In addition, the food primarily consists of wild sugarcane Saccharum species. According to Coombs \& Vlitos (1978) estimation, the standing biomass of sugarcane is $100 \mathrm{MT} /$ ha fresh weight or $35 \mathrm{MT} /$ ha dry weight, which gives a fresh/dry ratio of $100 / 35$. So, one rhino eats approximately $21-28 \mathrm{~kg} /$ day of dry weight. Assuming the mid value of this range, $24.5 \mathrm{~kg} /$ day, the annual food requirement of one animal is $24.5 \mathrm{~kg} /$ day x 365 day/year = 8.9 Tons/year.

Furthermore, Dinerstein (2003) calculated $0.34 \mathrm{~kg} /$ $\mathrm{m}^{2}$ dry weight of Saccharum in Chitwan. Thus in the home range of $400 \mathrm{ha}$, we would have a total of 3400 $\mathrm{kg} / \mathrm{ha} \times 400$ ha $=1,360$ Tons of dry food if it is covered entirely by grass. According to Dinerstein \& Price (1991) about 39 animals have been reported to use $3.2 \mathrm{~km}^{2}$ (320ha) area of prime habitats mostly composed of Saccharum and riverine forests. Therefore, we assume 40 animals would use the 400ha of home range area. Then, 8.9 tons/year per animal $\times 40$ animals $=356$ Tons of food per year which represents a fraction $T f=356$ $/ 1360=0.26$. However, there are no data available to estimate parameter Tc. We assumed that 12 ha out of 400 ha would be sufficient cover, and therefore $T c=$ $12 / 400=0.03$. Because of its uncertainty we will use sensitivity analysis as described below.

\section{Sensitivity Analysis}

The impact of cover on habitat suitability must take into account its seasonal importance. During monsoon season (4 months), we factor in the need for cover by using a geometric mean of food $S f$ and cover $S c$ suitability with a weight factor $a$. However, during the rest of the year ( 8 months), the animals do not need cover and food suitability accounts for HSI. The final HSI model is then a weighted arithmetic mean of the monsoon and offmonsoon suitability.

$$
H S I=\frac{4}{12}\left(S f^{a} \times S c^{(1-a)}\right)+\frac{8}{12} S f
$$

For parameter $a$, we estimated that food is much more important than cover and assigned a value of $a=0.8$ (4 times more important). In order to study the potential error that the arbitrary selections of $a$ and Tc may produce, we conducted sensitivity analysis by varying $a$ and $T c$ by $\pm 20 \%$ around their nominal values $(a=0.8, T c=0.03)$.

Figure 3 shows the effect of varying parameter $a$. As
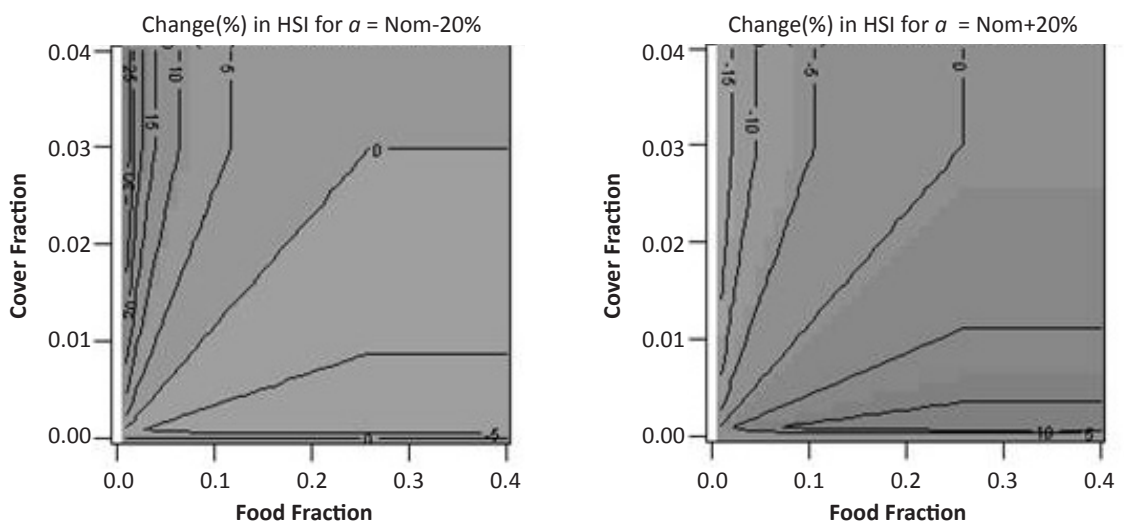

Figure 3. Effects of varying parameter $a=$ Slide 1 

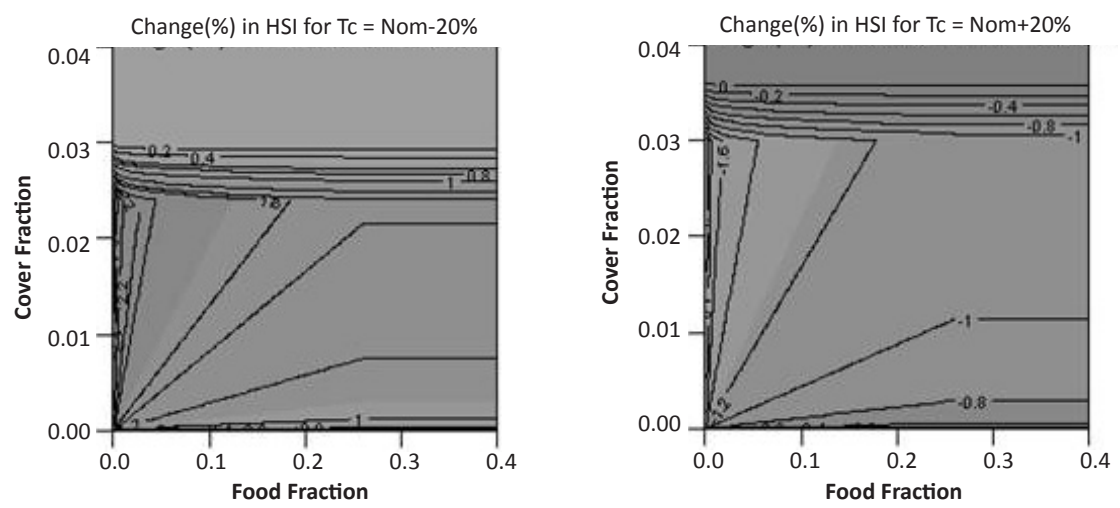

Figure 4. Effects of varying parameter Tc. = Slide 2

expected, for values of $x f, x c$ around or exceeding the corresponding threshold values the HSI is insensitive to changes in $a$. Only for very low values of fraction of food the HSI is more sensitive to $a$, reaching values of up to $25-30 \%$ change in HSI. Figure 4 shows the effect of varying parameter Tc. As before, for values of $x f, x c$ exceeding the corresponding threshold the HSI is insensitive to changes in Tc. Only for very low values of fraction of cover the HSI is more sensitive to Tc and represents less than 1-2\% change. Therefore, the uncertainty with respect to $T c$ is very small.

From this sensitivity analysis we conclude that the HSI value of a pixel could change with uncertainty in parameter $a$ for very low values of fraction of food. Moreover, it will not vary due to uncertainty in this parameter as long as the neighborhood around that pixel has fractions of food larger than the threshold $T f=0.26$ or 10 ha in 400 ha. Therefore, the HSI map will only be relatively uncertain for outside or edge grassland patches. This uncertainty is further reduced by the following classification of pixels into four classes (as explained below) - highly unsuitable, unsuitable, moderately suitable and suitable habitat types. Since all areas of low HSI values (which are relatively uncertain values) will be classified as either highly unsuitable, unsuitable or moderately suitable. The resultant HSI map pixels had values ranging from 0 to 1 . We needed to group the values between 0 and 1 into different classes that represented different habitat types and that in turn reflected habitat conditions. For example, pixels with low values such as $0.01,0.10,0.14,0.23$ etc reflected poor habitat conditions (these pixels either had less cover or food or vice versa) as compared to pixel values of $0.5,0.8$ and so on. Thus, higher pixel values indicated favorable habitat conditions. And to assign the pixels into different habitat types, we selected natural breaks (Jenks) as classification method in ArcMap and derived four classes as shown in Fig. 5.

We selected this method primarily because we wanted to find the breaks (high jumps) in the pixel data values of 0 and 1 . The break serves as a boundary while delineating classes. For example, pixels with values from $0-0.22$ were grouped in one class and pixels with values from $0.22-0.48$ were grouped in another class and so forth. In this case, the boundary lies at pixels with 0.22 values. In order to use these classes in FRAGSTATS (decimals are not accepted), we further assigned integer values of $1,2,3$ and 4 to represent the four habitat categories ( 1 = highly unsuitable, 2 = unsuitable, $3=$ moderately suitable and $4=$ suitable habitat pixels) (Fig. 5). We converted HSI map into ASCll text file and calculated metrics. We carefully selected metrics relevant to the habitat requirements of the rhinoceros and that met our objectives (Table 2). Our primary interests were (1) to find the size of the individual patch (2) to find the amount and distribution of a particular patch type and (3) to find whether particular patch types are contiguous or fragmented. And to meet our first objective, we selected AREA metric at patch level. This is a useful metric as many vertebrates including rhino require suitable habitat patches larger than some minimum size. For example, the average home range of a rhino is $\sim 400$ ha. We selected CA/TA (Total Area), PLAND (Percentage of Landscape) and NP (Number of Patches) at class level to satisfy the second objective. These metrics quantify composition of the patches. And to meet the third objective, we selected COHESION (Patch Cohesion Index) to find physical connectedness of particular patch type. This metric measures configuration of a patch to its neighbors in the landscape. 


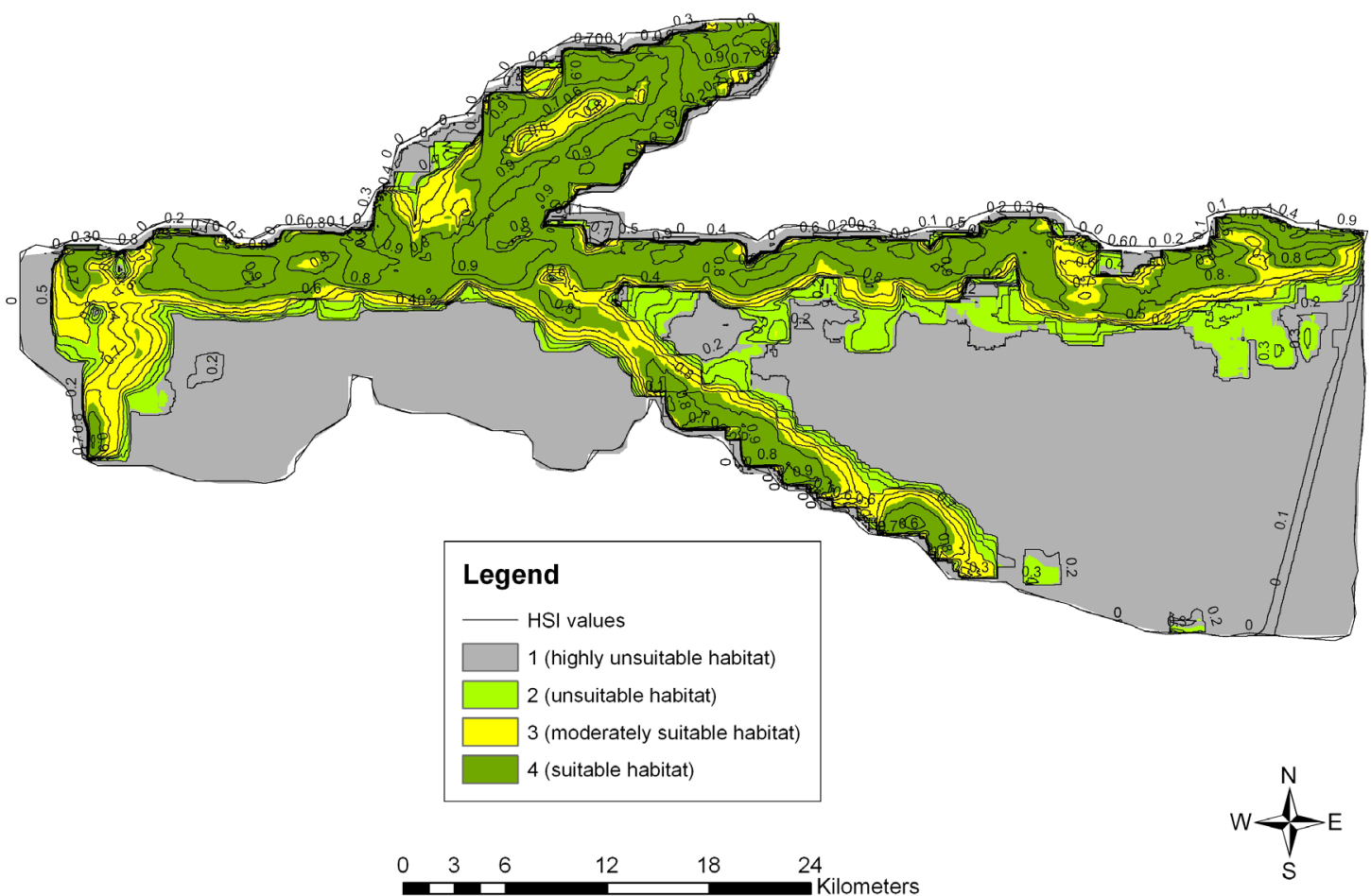

Figure 5. Habitat Suitability Index Map.

\section{RESULTS}

\section{Vegetation Classification}

The overall accuracy was about $70 \%$ with more than $80 \%$ of water, sand, sal forest and mixed forest pixels accurately classified (Table 1). KHAT index for water and sand exhibited more than $90 \%$ agreement between reference and classified pixels. Whereas it was less than $40 \%$ for agriculture indicating $60 \%$ of the pixels were incorrectly classified. The classification of sand, sal, and mixed forest was satisfactory. It was easy to create an area of interest (AOI) for sal and sand pixels as $70 \%$ of the park area is covered by sal forest and sand pixels were easy to select based on the location and spectral profile. The three major rivers had sandy banks of relative thickness running parallel to them that made easier to create AOI. Once a group of pixels belonging to the same class is identified, ERDAS automatically select areas with similar pixels under the supervision of the user - a tool commonly employed during supervised classification. On the other hand, wetland, grassland and agriculture were classified with $75 \%$ and $50 \%$ accuracy. The reason for low accuracy of grassland category may have resulted from confusion of agriculture and grass pixels, a typical situation in such studies. The growth stage or the height of the crops and the grass could have been similar when this image was taken. The agricultural land contains some of the settlement and grassland pixels. Similarly, wetland pixels could be confused with other water bodies. The largest wetland area is actually the outlet of one of the major lakes, Tamar Tal (Tamar Lake). It is located closer to the confluence of the three rivers; and when the lake is inundated during the monsoon season, water overflows to this area. The purpose of the second visit to the field was to confirm vegetation and location of this area. The fieldwork revealed a secondary succession of grassland in the outlet. While one side of the outlet was covered with marshy vegetation, the other side flourished with grassland. The marshy vegetation would eventually convert into grassland that would serve as additional habitat for the Greater One-horned Rhinoceros. The area or the lake could have overflowed when this image was taken in 2003. The spectral profiles of these pixels also exhibit the nature of vegetation that is submerged in water. New classification routines are needed that can tease apart detailed reflectance patterns that are essential to distinguish agriculture, grassland, and settlement pixels. This increases need in field identification of these classes, and the use of higher-resolution imagery is another promising alternative.

\section{HSI and Habitat Fragmentation}

For One-horned Rhinoceros, food is considered to be 
the most important factor of their habitat components with some seasonal cover. Thus, we assigned a value of 0.8 for parameter $a$. We calculated threshold values for food to be $T f=0.26$. And for cover threshold, we assumed 12 ha out of 400 ha (mean annual home range) would be sufficient to hold one animal and $T c=0.03$. We performed sensitivity analysis by varying the nominal values of $a$ and $T c$ by $\pm 20 \%$. Interestingly, we found HSI is only sensitive to $a$ with low values of fractions of food $(x f)$ and cover $(x c)$. In other words, the uncertainty of parameter $a$ is minimum if food and cover availability is more than their respective thresholds. The small uncertainty of parameter Tc suggested that forests are used less frequently or used seasonally but it is a critical component of habitat requisites. The HSI map showed distinct spatial pattern, with high values of HSI along the areas near water bodies and adjacent grasslands and edges of sal forests with low values in the inland areas (Fig. 5).

The metric result showed presence of 476 patches that belong to four different habitat types (Table 3 and 4). AREA metric revealed the largest patch $(51,065.73$ ha) belonged to suitable habitat type (Table 3 ). The total area of suitable habitat is $51,781.95$ ha or $517.82 \mathrm{~km}^{2}$ that include some buffer zone and agricultural areas outside the park boundary. Moreover, the lowest number of patches (NP $=18$ ) and highest value of connectivity metrics (99.84) for suitable habitat to support its homogeneity across the landscape especially along the river boundaries (Table 4). This indicates that rhinos inhabiting habitats near the three major rivers can travel
Table 2. FRAGSTATS metrics at patch and class levels. Landscape level metrics were not analyzed because of their little interpretative value and identical behavior at class level.

\begin{tabular}{|l|l|}
\hline Metric & Designation \\
\hline Patch Level & \\
\hline Area/Density/Edge: & AREA \\
\hline Patch Area & \\
\hline Class Level & \\
\hline Area/Density/Edge: & CA/TA \\
\hline Class Area & PLAND \\
\hline Percentage of class & NP \\
\hline Number of patches & \\
\hline Connectivity & \\
\hline Cohesion &
\end{tabular}

undeterred using river banks as a migrating route. This is corroborated by the findings of Dinerstein \& Price (1991) that discovered frequent rhino movement from fareast to the Sauraha subpopulation. However, resident rhinos of Reu and Rapti may be permanently separated by contiguous blocks of highly unsuitable habitat of sal forest and so are the subpopulation of the BandarjholaNarayani River and the Sauraha by extensive blocks of agriculture and settlements. The rhinos can use river banks but previous works have indicated that they do not travel far if prime habitats are nearby, i.e., abundant productive floodplains. Other metrics such as PLAND indicated highly unsuitable habitat (mostly sal forests) occupied the largest percentage of the landscape (39\%)

Table 3. Patch metric results

\begin{tabular}{|c|c|c|c|c|c|c|c|c|c|c|c|}
\hline PID & TYPE & AREA & PID & TYPE & AREA & PID & TYPE & AREA & PID & TYPE & AREA \\
\hline 4 & 1 & 0.09 & 247 & 2 & 0.09 & 332 & 3 & 0.09 & 82 & 4 & 0.09 \\
\hline 455 & 1 & 0.09 & 367 & 2 & 0.18 & 96 & 3 & 0.18 & 28 & 4 & 0.18 \\
\hline 459 & 1 & 0.09 & 445 & 2 & 0.27 & 423 & 3 & 0.27 & 132 & 4 & 0.27 \\
\hline 6 & 1 & 0.18 & 152 & 2 & 0.36 & 411 & 3 & 0.36 & 252 & 4 & 0.72 \\
\hline 16 & 1 & 0.18 & 299 & 2 & 0.45 & 88 & 3 & 0.45 & 23 & 4 & 1.08 \\
\hline 385 & 1 & 0.18 & 319 & 2 & 0.54 & 366 & 3 & 0.54 & 63 & 4 & 1.35 \\
\hline 392 & 1 & 0.18 & 440 & 2 & 0.63 & 413 & 3 & 0.63 & 52 & 4 & 1.53 \\
\hline 399 & 1 & 0.18 & 144 & 2 & 0.72 & 433 & 3 & 0.72 & 131 & 4 & 1.98 \\
\hline 402 & 1 & 0.18 & 182 & 2 & 0.9 & 86 & 3 & 0.81 & 166 & 4 & 2.07 \\
\hline 43 & 1 & 0.27 & 258 & 2 & 0.99 & 119 & 3 & 0.9 & 371 & 4 & 14.22 \\
\hline 224 & 1 & 0.27 & 95 & 2 & 1.26 & 127 & 3 & 0.99 & 425 & 4 & 25.29 \\
\hline 355 & 1 & 0.27 & 133 & 2 & 1.35 & 246 & 3 & 1.08 & 475 & 4 & 178.2 \\
\hline 469 & 1 & 0.27 & 222 & 2 & 1.53 & 393 & 3 & 1.17 & 135 & 4 & 488.7 \\
\hline 36 & 1 & 0.36 & 309 & 2 & 1.62 & 287 & 3 & 1.26 & 328 & 4 & 51065.73 \\
\hline
\end{tabular}


Table 4. Class metric result

\begin{tabular}{|c|c|c|c|c|}
\hline LID & CA (ha) & PLAND (\%) & NP & COHESION \\
\hline 1 & 56647.26 & 39.275 & 176 & 99.84 \\
\hline 2 & 21441.96 & 14.8661 & 98 & 99.67 \\
\hline 3 & 14362.92 & 9.9581 & 184 & 99.25 \\
\hline 4 & 51781.95 & 35.9013 & 18 & 99.94 \\
\hline & & & 476 & \\
\hline
\end{tabular}

followed by suitable habitat patches (36\%). Moderately suitable habitat patches are the most fragmented and the least in numbers as indicated by NP and COHESION metrics and occurred adjacent to the suitable habitat patches (Table 4).

\section{DISCUSSION}

\section{Vegetation classification}

The most valuable data-land-cover types, soil profile, plant composition, and density of canopy cover-were determined by the field study. Field verification of land cover types proved to be the most effective method and best suited to using a GPS unit as the device of choice. Ground-truth data along with pictures of field activities compensated the paucity of previously tested data such as aerial photos and assisted in classifying the vegetation types represented in CNP. We used the supervised method to classify the image into eight land cover classes - water, sand, settlement, wetland, grassland, agriculture, mixed and sal forest. We employed a new technique to assess classification accuracy. Generally, random points created in ERDAS or aerial photos or previous data are used to assess the accuracy of a thematic map (Anderson et al. 1976; Congalton \& Green 1999; Salovaara et al. 2005). For this project, we used ground-truth points to classify, test and enhance accuracy. The overall classification accuracy was $70 \%$. Most categories including water, sand, sal and mixed forest, and wetland were classified with more than $80 \%$ accuracy. The low accuracy value for grassland and agriculture could be attributed to the confusion of their pixels. Depending on growth stage and season, agricultural pixels are easily mistaken for grass and it is a common and persisting problem in remote sensing. Moreover, grasslands near Tamar Lake are classified as mixed or sal forest; this classification may be due to the tall nature of these grasslands. With a height ranging from $6-8 \mathrm{~m}$, sometimes they grow with small trees and shrubs and can completely overshadow them. To achieve more accuracy for the grassland, we recommend the use of higher-resolution imagery.

\section{HSI model and habitat fragmentation}

We constructed two maps (food and cover) from the land cover map. We used two land cover categories, i.e., agriculture and grassland to make food map and used sal forest cover type to make cover map. And we ran focal neighborhood statistics to calculate the proportion of food and cover in $70 \times 70$ cell neighborhood that represented mean annual home range of an adult rhino. In this way, we developed a heuristic HSI model for the Greater One-horned Rhinoceros based on a process-oriented approach. In other words, we merely attempted to develop HSI using habitat use parameters that were collected from extensive literature reviews of spacing behavior, biology, and daily routine of a rhino (Laurie 1982; Dinerstein \& Wemmer 1988; Lekhmul 1988; Dinerstein 1989; Dinerstein \& McCracken 1990; Dinerstein \& Price 1991; Jnawali \& Wegge 1993; Dinerstein 2003). We used this information to conduct neighborhood analysis, to select, construct and build $\mathrm{HSI}$ and to assign threshold to the parameters. Our sensitivity analysis confirmed about 0.03 cover and 0.26 of food in $\sim 400$ ha is sufficient to sustain a rhino crash (a group of rhinos). As noted above, this research applied habitat use to generate an HSI model in an attempt to examine whether such HSIs can be developed for the mega herbivore; and after conducting these procedures, we determined that the development of the indices was feasible. However, validation of the results of any HSIs require rigorous field study involving home range, telemetric studies for years, and habitat use (Dettki et al. 2003). We think this method will be effective and useful if used with data that are acquired in the manner explained above and if such data are available we can apply these procedures to study the habitat suitability of other large ungulates in the study region or elsewhere.

We demonstrated that the careful selection of FRAGSTATS metrics yields interesting and useful results. We quantified the four habitat patches with respect to patch size, number of patches and connectivity of corresponding patch types. This would provide much needed data on the habitat of the rhinoceros (especially on the remaining suitable habitat patches). COHESION metrics revealed the contiguous nature of suitable habitat patches that is vital to the survival of rhinos and other sympatric species. In the case of rhinos, this means CNP landscape facilitates ecological flows, i.e., there is constant movement of animals among 
habitat patches thus reducing the threat of extinction threshold. As noted above, the rhinos seek out the most nutritious of all grass species (Saccharum) that are available year round. These grass species thrive on the floodplains and are maintained by periodic monsoon floods. It would be interesting to find core habitats, number of core habitats, edge density, diversity and several others and FRAGSTATS produces several metrics to study these aspects of a landscape. However, lack of fine scale data such as edge effect on rhino population or individual or how a rhino perceives its habitat and the actual size of the habitat etc limited our study. We relied heavily on the studies that were conducted mostly on the ecological and biological aspects of a group of rhinoceros, not on individuals. Laurie (1982), Dinerstein \& Price (1991), and Subedi (2012) did use conventional radio-telemetry and GPS collars to study habitat use but they focused mainly in finding mean annual home range, habitat preference, seasonal distribution and feeding habits. Thus, study of effect of edge on a rhino movement is still lacking and such studies could provide vital information about distribution and movement of a rhino within its suitable habitat and influence on its behavior due to adjoining unsuitable habitat - an open area for future study. Further, we examined processoriented approach to model the rhino habitat and found it can be ecologically meaningful if selection of the used environmental variables is based on the habitat requirements of the target species. And if the variables are correctly identified, they enable us to understand the effects of changes in the landscape on the model outcome.

\section{Management Implications}

After a decade long political unrest from 1995 to 2006, Nepal regained peace and stability in 2007 when the Maoists gave up arms in April of 2006 (Martin et al. 2008; Martin \& Martin 2010). Since then, conservation efforts resumed and poaching was reduced drastically with only one rhino poached in 2011 and one in 2012 (Martin et al. 2013). Currently, CNP has 503 rhinos and other strongholds such as Bardia National Park and Shuklaphanta Wildlife Reserve saw increase as well (WWF 2012; Martin et al. 2013). These areas, especially CNP, also saw increase in tourist visits that in turn led to increase in revenues (Martin et al. 2008, 2013; Martin \& Martin 2010). Thus, Nepal has once again proved these mega-vertebrates can be brought back from the brink of extinction with stable government and relative peace. However, the increase in rhino numbers warrants more vigorous conservation efforts in addition to existing ones.
Therefore, we suggest following recommendations:

(1) We found approximately $517.82 \mathrm{~km}^{2}$ suitable habitats available. Fragmentation metrics such as lowest number of patches (NP $=18$ ) and highest connectivity value of 99.84 indicates they are less fragmented and highly contiguous as compared to other habitat types - crucial feature to reduce extinction thresholds and to facilitate ecological energy flows. The largest patch size is $510.63 \mathrm{~km}^{2}$ and is mostly located near floodplains. Similarly, Kafley et al. (2009) reported the presence of $614 \mathrm{~km}^{2}$ of suitable habitats in similar areas, which is more than $100 \mathrm{~km}^{2}$ to what we found. This increase is attributed to the addition of $171 \mathrm{~km}^{2}$ of suitable Sal forest habitats (rhinos could use these areas) to $443 \mathrm{~km}^{2}$ that are already inhabited by rhinos (Kafley et al. 2009). We conducted our fieldwork in the summers of 20042005 and used GIS, remote sensing and GPS locations of food and cover to build our suitability maps. Kafley et al. (2009) used GIS, remote sensing and presence only data (obtained from rhino census of 2008) to build and MAXENT modeling technique to validate suitability maps. Our methods varied but produced similar results. There was an interval of three years in the above studies. We suggest similar studies can be conducted using rhino census of 2011, GIS and remote sensing. Further, a regular ( 5 or 10 year period) multi-temporal change detection analysis using our results as base maps, could reveal dynamism of the floodplain habitats. Such studies could provide continuity in monitoring of suitable and target moderately suitable habitats for restoration.

(2) The availability of large areas of suitable habitats indicates CNP has far greater carrying capacity for rhinos than it currently holds. However, current studies inform that above habitats are deteriorating at an alarming rate (Lahkar et al. 2011; Subedi 2012). Both studies indicate the slow and steady intrusion of exotic invasive species such as Mikania micrantha, Mimosa diplotricha, and Chromolaena odorata may overshadow current conservation success in rhino strongholds including Kaziranga National Park, Assam (Lahkar et al. 2011; Subedi 2012). In CNP, the imminent impact was observed on the habitat use as the home range increased from $\sim 4.3 \mathrm{~km}^{2}$ (Dinerstein 2003) to $20.54 \pm 6.06$ $\mathrm{km}^{2}$ (Subedi 2012). We recommend the use of our HSI and vegetation maps, and habitat patch data in addition to ongoing concerted efforts of the Zoological Society of London, Department of National Parks and Wildlife Conservation, National Trust for Nature Conservation, and $\mathrm{CABI}$, to control aforementioned exotic species. 


\section{REFERENCES}

Anderson, J.F., E.E. Hardy, J.T. Roach \& R.E. Witmer (1976). A land use and land cover classification system for use with remote sensor data, U.S. Geological Survey Professional Paper 964, U.S. Geological Survey, Washington, DC, 28pp.

Allen, A.W. (1982). Habitat suitability index models: Beaver. U.S. Dept. Int., Fish Wildl. Servo FWS/OBS-82/10.30, 20pp.

Berlanga-Robles, C.S.A. \& A. Ruiz-Luna (2002). Land use mapping and change detection in the coastal zone of northwest Mexico using remote sensing techniques. Journal of Coastal Research 18: 514-522.

Cohn, J.P. (1988). Halting the Rhino's Demise. Bioscience 38: 740-744.

Congalton, G.R. \& K. Green (1999). Assessing the accuracy of Remotely Sensed Data: Principles and Practices. Lewis Publishers, CRC Press, New York.

Choi, M., Y.K. Rae, N. Myeong-Ryong \& K.H. Oh (2005). Fusion of Multispectral and Panchromatic Satellite Images Using the Curvelet Transform. IEEE Geoscience and remote sensing letters - 2.

Coombs, J. \& A.J. Vlitos (1978). An assessment of the potential for biological solar energy utilization using carbohydrates produced by higher plant photosynthesis as chemical feedstock. Vol. 2. Proceedings of International Solar Energy Society Congress, New Delhi, India, Pergamon Press, New York.

Dettki, H., R. Lofstran \& L. Edenius (2003). Modeling habitat suitability for Moose in coastal northern Sweden: Empirical vs. Processoriented Approaches. Royal Swedish Academy of Sciences. Ambio 8(32): 549-556.

Dinerstein, E. (1989). The foliage-as-fruit hypothesis and the feeding behavior of South Asian ungulates. Biotropica 21: 214-218.

Dinerstein, E. (2003). The Return of the Unicornis - The Natural History and Conservation of the Greater One-horned Rhinoceros. Biology and Resource Management Series. World Wildlife Fund, Washington D.C., 320pp.

Dinerstein, E. \& C. Wemmer (1988). Fruits Rhinoceros eat: dispersal of Trewia nudiflora in lowland Nepal. Ecology 69: 1768-1774.

Dinerstein, E. \& G.F. McCracken(1990). Endangered Greater one-horned Rhinoceros carry high levels of genetic variability. Conservation Biology 4: 417-422; http://dx.doi.org/10.1111/j.1523-1739.1990. tb00316.x

Dinerstein, E. \& L. Price (1991). Demography and Habitat use by Greater One-horned Rhinoceros in Nepal. The Journal of Wildlife Management 55(3): 401-411.

Hardison, T. (2003). Application of remote sensing and GIS to modeling fire for vegetative restoration in northern Arizona. MS Thesis. Department of Environmental Science and Geography, University of North Texas, Denton, 57pp.

Harini, N. \& M. Gadgil (1999). Biodiversity assessment at multiple scales: Linking remotely sensed data with field information. Ecology 96: 9154-9158.

Harini, N., S. Pareeth, B. Sharma, C.M. Schweik \& K.R. Adhikari (2008). Forest fragmentation and regrowth in an institutional mosaic of community, government and private ownership in Nepal. Landscape Ecology 23: 41-54; http://dx.doi.org/10.1007/s10980-007-9162-y

Innes, J.L. \& B. Koch (1998). Forest biodiversity and its assessment by remote sensing. Global Ecology and Biogeography Letters 7: 397419; http://dx.doi.org/10.1046/j.1466-822X.1998.00314.x

IUCN (2012). IUCN Red List of Threatened Species. <www.iucnredlist. org> Downloaded on 11 June 2013

Jnawali, S.R. \& P.W. Wegge (1993). Space and habitat use by a small reintroduced population of Greater One-horned Rhinoceros (Rhinoceros unicornis) in Royal Bardia National Park in Nepal - a preliminary report, pp. 208-217. In: Ryder, A.O. (ed.). Rhinoceros Biology and Conservation. Proceedings of an international conference. Zoological Society of San Diego, San Diego, CA.

Jnawali, S.R. (1995). Population ecology of Greater One-horned Rhinoceros (Rhinoceros unicornis) with particular emphasis on habitat preference, food ecology and ranging behavior of a reintroduced population in Royal Bardia National Park in lowland
Nepal. PhD Thesis. Agricultural University of Norway.

Kafley, H, M. Khadka \& M. Sharma (2009). Habitat Evaluation and Suitability Modeling of Rhinoceros unicornis in Chitwan National Park, Nepal: A Geospatial Approach. XIII World Forestry Congress. Buenos Aires, Argentina.

Lahkar, P.B., B.K. Talukdar \& P. Sharma (2011). Invasive species in grassland habitat: an ecological threat to the Greater One-horned Rhino (Rhinoceros unicornis). Pachyderm 49: 33-39.

Laperriere, J., P. C. Lent, W.C. Gassaway \& F.A. Nodler (1980). Use of landsat data for moose habitat analyses in Alaska. Journal of Wildlife Management 44: 881-887.

Laurie, A. (1982). Behavioral ecology of the Greater One-horned Rhinoceros (Rhinoceros unicornis). Journal of Zoology 196: 307341; http://dx.doi.org/10.1111/j.1469-7998.1982.tb03506.x

Lekhmul, J. (1989). The Ecology of South Asian Tall-grass Community. PhD Thesis. University of Washington, Seattle, 214pp.

Lott, D.F. \& M. McCoy (1995). Asian Rhinos Rhinoceros unicornis on the run - impact of tourist visits on one population. Biological Conservation 73: 23-26; http://dx.doi.org/10.1016/00063207(95)90053-5

Martin, E. \& C. Martin (2010). Enhanced community support reduces rhino poaching in Nepal. Pachyderm 48: 48-56.

Martin, E., C. Martin \& L. Vigne (2008). Recent political disturbances in Nepal threaten rhinos: lessons to be learned. Pachyderm 45: 98-107.

Martin, E., C. Martin \& L. Vigne (2013). Successful reduction in rhino poaching in Nepal. Pachyderm 54: 66-73.

McClain, B.J. \& W.F. Porter (2000). Using satellite imagery to assess large-scale habitat characteristics of Adirondack Park, New York, USA. Environmental Management 26: 553-561.

McGarigal, K. \& B.J. Marks (1994). FRAGSTATS: spatial pattern analysis program for quantifying landscape structure. United States Department of Agriculture.

Mishra, H.R. (1982a). The Ecology and Behaviour of Chital (Axis axis) in the Royal Chitwan National Park, Nepal. PhD Thesis. University of Edinburgh, 240pp.

Mitchell, M.S., J.W. Zimmerman \& R.A. Powell (2002). Test of habitat suitability index for black bears in the southern Appalachians. Wildlife Society Bulletin 30: 794-808.

Nepal, S.K. \& K.E. Weber (1995). The quandary of local people-park relations in Nepal's Royal Chitwan National Park. Environmental Management 19: 853-866.

Odden, M., P. Wegge \& T. Storaas (2005). Hog Deer (Axis porcinus) need threatened tallgrass floodplains: a study of habitat selection in lowland Nepal. Animal Conservation 8: 99-104; http://dx.doi. org/10.1017/S1367943004001854

Owen-Smith, R.N. (1988). Megaherbivores: The Influence of Very Large Body Size on Ecology. Cambridge University Press, 364pp.

Porwal, M.C., P.S. Roy \& V. Chellamuthu (1996). Wildlife habitat analysis for 'Sambar' (Cervus unicolor) in Kanha National Park using remote sensing. International Journal of Remote Sensing 17: 26832697; http://dx.doi.org/10.1080/01431169608949100

Rawat, G.S. (2005). Vegetation dynamics and management of Rhinoceros habitat in Duars of West Bengal: an ecological review. National Academy Science Letters - India 28: 177-184.

Rookmaaker, L.C. (1984). The former distribution of the Indian Rhinoceros (Rhinoceros unicornis) in India and Pakistan. Journal of the Bombay Natural History Society 80(3): 555-563.

Salovaara, K.J., S. Thessler, R.N. Malik \& H. Tuomisto (2005). Classification of Amazonian primary rain forest vegetation using Landsat ETM plus satellite imagery. Remote Sensing of Environment 97: 39-51; http://dx.doi.org/10.1016/j.rse.2005.04.013

Sharma, B.D., J. Clevers, R.D. Graaf \& N.R. Chapagain (2004). Mapping Equus kiang (Tibetan Wild Ass) Habitat in Surkhang, Upper Mustang, Nepal. Mountain Research and Development 24: 149-156; http:// dx.doi.org/10.1659/0276-4741(2004)024[0149:MEKTWA]2.0.CO;2

Studsrod, J.E. \& P. Wegge (1995). Park-people relationships - the case of damage caused by park animals around the Royal-BardiaNational-Park, Nepal. Environmental Conservation 22: 133-142; 
http://dx.doi.org/10.1017/S0376892900010183

Subedi, N. (2012). Effect of Mikania micrantha on the demography, habitat use, and nutrition of Greater One-horned Rhinoceros in Chitwan National Park, Nepal. PhD Thesis. Forest Research Institute University, Dehradun, Uttarakhand, 209pp.

Talukdar, B.K., R. Emslie, S.S. Bist, A. Choudhury, S. Ellis, B.S. Bonal, M.C. Malakar, B.N. Talukdar \& M. Barua (2008). Rhinoceros unicornis. The IUCN Red List of Threatened Species. Version 2014.2. <www.iucnredlist.org>. Downloaded on 16 September 2014.

Wegge, P., A.K. Shrestha \& S.R. Moe (2006). Dry season diets of sympatric ungulates in lowland Nepal: competition and facilitation in alluvial tall grasslands. Journal of Ecological Restoration 21: 698706; http://dx.doi.org/10.1007/s11284-006-0177-7

WWF (2012). Nepal rhino census shows increase. Available from <http://wwf.panda.org/?200112/Collective-conservation-effortsboosted- rhino-population-in-Nepal>
Author Details: VIVEK THAPA - an independent researcher and not affiliated with any organizations. Currently, he is writing proposal to Texas Parks and Wildlife Department to conduct habitat analysis and population demography of White-tailed Deer in Hagerman National Wildlife Refuge, Texas, USA. He aims to use GIS, remote sensing, FRAGSTATS and statistical analysis to conduct aforementioned project. MIGUEL F. ACEVEDO - in addition to his departmental affiliations he is Faculty in the Graduate Program in Environmental Sciences, UNT. His work integrates environmental monitoring and modeling to understand the dynamics of environmental and ecological systems, and to provide socially relevant results concerning pollutants, land use change and climate variability. KUL PRASAD LIMBU - affiliated with Tribhuvan University, currently, he is involved in venomous snake-bite epidemiology and their taxonomy. His primary research interests include wildlife and conservation biology. 